\title{
Immunoelectron Microscopic Observations on the Localization of Fibronectin in Normal Human Lung
}

\author{
Kiminiko Takusagawa, Noboru Asoo, Toshio Sato, \\ Hiromi Nagai, Masakichi Motomiya and Kiyoshi Konno \\ Department of Internal Medicine, the Research Institute for \\ Tuberculosis and Cancer, Tohoku University, Sendai 980
}

\begin{abstract}
Takusagawa, K., Asoo, N., Sato, T., Nagai, H., Мотomiya, M. and Konno, K. Immunoelectron Microscopic Observations on the Localization of Fibronectin in Normal Human Lung. Tohoku J. exp. Med., 1986, 150 (2), 209-223 — The localization of fibronectin was examined in normal human lung using immunoelectron microscopy. Fibronectin staining was present not only in the endothelial, alveolar epithelial and bronchial epithelial basal laminae and associated with interstitial collagen fibrils and elastic fibers, but also in basal laminae of fibroblasts and smooth muscle cells. There was a periodicity in the staining of fibronectin on collagen fibrils. Reaction products against fibronectin were present in intracellular organelle including cisternae of smooth endoplasmic reticulum of endothelial cells and those of rough endoplasmic reticulum of fibroblasts. No other cells contained reaction products. The localization of fibronectin was compared with that of ruthenium red staining in normal human lung. The localization of fibronectin was consistent with that of proteoglycan.

fibronectin; immunoelectron microscopy; human lung
\end{abstract}

Fibronectin is a plasma and stromal glycoprotein with a molecular weight of 440,000 composed of two similar subunits held together by disulfide bonds (Hynes 1981 ; Hynes and Yamada 1982 ; Ruoslahti et al. 1981, 1982). It is a polyfunctional molecule with well-characterized cell-, collagen-, and heparin-binding properties (Hynes 1981; Hynes and Yamada 1982; Ruoslahti et al. 1981, 1982). Fibronectin is synthesized by a number of cell types in vitro, including lung fibroblasts, endothelial cells, type II alveolar epithelial cells and smooth muscle cells (Muir et al. 1976; Baum et al. 1977; Jaffe and Mosher 1978; Sage et al. 1983). Fibronectin is widely distributed in normal vertebrate tissues such as connective tissues and basement membranes (Linder et al. 1975; Stenman and Vaheri 1978; Wartiovaara et al. 1979; Labat-Robert et al. 1981). Immunofluorescent staining of adult human lung revealed fibronectin to be generally distributed in alveolar basement membrane (Stenman and Vaheri 1978). To our knowledge, a few ultrastructural observations of fibronectin have been made in experimental animal lungs (Rosenkrans et al. 1983 ; Gil and Martinez-

Received May 28, 1986; accepted for publication October 1, 1986. 
Hernandez 1984 ; Torikata et al. 1985) and in normal and fibrotic human lungs (Clark et al. 1983 ; Takusagawa et al. 1983 ; Torikata et al. 1985). The localization of fibronectin in alveolar basement membranes remains controversial at the ultrastructural level. Torikata et al. (1985) reported that alveolar basement membranes were uniformly stained in both hamster and human lungs. However, rat alveolar basement membrane staining was either nonuniform (Gil and Martinez-Hernandez 1984) or absent (Rosenkrans et al. 1983). In this study the ultrastructural localization of pulmonary fibronectin was investigated by indirect immunoperoxidase method. We compared the distribution of fibronectin with that of proteoglycans in normal human lung which had been described elsewhere (Takusagawa et al. 1982). The proteoglycans have been known to have an affinity to fibronectin (Perkins et al. 1979; Hynes and Yamada 1982 ; Ruoslahti et al. 1982 ; Laterra et al. 1983). Both fibronectin and proteoglycans are present in intercellular matrix. The relationship between them has not been known at the ultrastructural level.

\section{Materials and Methods}

The specimens were obtained from four patients who underwent open thoracotomy. All specimens were macroscopically normal. The specimens were cut into $1 \times 1 \times 0.5 \mathrm{~cm}$ and fixed in periodate-lysine-paraformaldehyde (McLean and Nakane 1974) for $6 \mathrm{~h}$ at $4^{\circ} \mathrm{C}$.

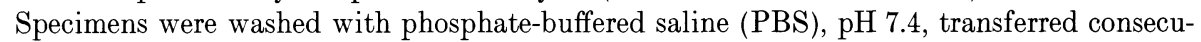
tively to $10 \%$ sucrose in PBS, $15 \%$ sucrose in PBS, $20 \%$ sucrose in PBS every $4 \mathrm{hr}$ and finally to $20 \%$ sucrose contained $5 \%$ glycerol in the same buffer for $1 \mathrm{hr}$. After embedding in Tissue Tek II (Miles Lab. Naperville, ILL, USA), they were frozen rapidly in dry ice acetone and frozen sections were cut at approximately $6 \mu \mathrm{m}$. The sections were placed on albumin-coated glass slides and immediately subjected to the immunoperoxidase staining procedure according to the method of Dixon and Burns (1982). They were rinsed in PBS for $30 \mathrm{~min}$ at room temperature. After overnight incubation in a moist chamber with rabbit anti-human fibronectin $\mathrm{F}\left(\mathrm{ab}^{\prime}\right)_{2}$ (Cappel Lab. Cochranville, PA, USA) diluted $1: 10$ in $\mathrm{PBS}$ at $4^{\circ} \mathrm{C}$, the sections were washed several times in $\mathrm{PBS}$ at room temperature before overnight exposure at $4^{\circ} \mathrm{C}$ to horseradish peroxidase (HRPO) labeled sheep anti-rabbit $\mathrm{F}\left(\mathrm{ab}^{\prime}\right)_{2}$ (Cappel Lab. Pa, USA) diluted $1: 16$ in PBS. Further washing in PBS for $6 \mathrm{~h}$ at room temperature was followed by development of the horseradish peroxidase with diaminobenzidine tetrahydrochloride and hydrogen peroxide in $0.05 \mathrm{M}$ Tris buffer (Graham and Karnovsky 1966). The sections were washed again in PBS for $6 \mathrm{~h}$ at room temperature. They were fixed in $1 \%$ osmium tetroxide for 30 min, dehydrated through graded ethanols and embedded in Epon 812. Thin sections were cut by a Porter Blum MT II microtome equipped with a diamond knife and were mounted on copper grids. They were observed in a Hitachi H-600 electron microscope with or without counterstaining with uranyl acetate and lead citrate. Photographs were taken at an accelerating voltage of $75 \mathrm{KV}$.

As controls, the specimens were incubated with PBS instead of the first antibody, rabbit anti-human fibronectin $\mathrm{F}\left(\mathrm{ab}^{\prime}\right)_{2}$, or were incubated with normal rabbit serum followed by sheep anti-rabbit fibronectin $\mathrm{F}\left(\mathrm{ab}^{\prime}\right)_{2}$-HRPO conjugates.

\section{Results}

The sections were not uniformly stained. Empty spaces in the cytoplasm were noted among interstitial cells, smooth muscle cells and epithelial cells, 
presumably due to preparative artifacts resulting from the ice crystal formation. In appropriately stained sections the reaction products were seen in basal laminae of endothelial (Figs. 1 and 2), alveolar epithelial (Fig. 3) and bronchial lining cells (Fig. 4). Fibronectin was most abundant in the stroma. The circumference of a bundle of collagen fibrils and of elastic fibers was stained by the antibody against fibronectin (Fig. 5). The reaction products were also observed on fine filaments, $3-4 \mathrm{~nm}$ in diameter and fine granules, $10 \mathrm{~nm}$ in width which were located throughout the stroma (Fig. 6). The dotted reaction products were noted along each of collagen fibrils (Figs. 7 and 8). The surface of collagen fibrils was also stained (Fig. 8). Intermediate filaments, $10-20 \mathrm{~nm}$ in diameter bound to dotted reaction products were distributed between collagen fibrils (Fig. 6). Fibronectin staining was also found in basal laminae of fibroblasts (Fig. 5) and smooth muscle cells (Fig. 9). A strand form of the reaction products extended from the basal lamina of fibroblast to surrounding bundles of collagen fibrils (Fig. 5). The reaction products were observed in pinocytotic vesicles of endothelial cells, fibroblasts and smooth muscle cells. Fibronectin staining was seen within the cisternae of the smooth endoplasmic reticula of endothelial cells (Fig. 2) and of the rough endoplasmic reticula of fibroblasts (Fig. 1). The cistern of endothelial cells opened into the basal plasmalemma and the content of the cisterns was connected with the basal lamina. The basal plasmalemma of endothelial cells, alveolar and bronchial epithelial cells was also stained.

All control sections were negative for fibronectin (Fig. 10).

\section{Discussion}

There are several difficulties in immunoelectronmicroscopy. Firstly, the penetration of the antibody into tissues will depend on the size of the antibody (Oberley et al. 1979 ; Courtoy et al. 1980 ; Dixon and Burns 1982 ; Fromme et al. 1982 ; Rosenkrans et al. 1983). In our study, staining of fibronectin was not uniform. Irregularity in the staining for immunoelectron-microscopy may be due to poor penetration of antibody. Secondly, due to the fixatives used the ultrastructural preservation of tissues in immunocytochemistry is worse than that of tissues fixed by conventional fixation with glutaraldehyde and osmium tetroxide. Fixatives used for immunocytochemistry occasionally destroy the antigenic determinants. A number of immunofluorescence studies have been carried out on the distribution of fibronectin in the lung (Stenman and Vaheri 1978; LabatRobert et al. 1981). However, the dimensions of many connective tissue components are well beyond the resolving power of the light microscope (MartinezHernandez and Amenta 1983). The resolution of immunoelectron microscopy is superior to that of light immunofluorescence microscopy. Another problem is a diffusion of diaminobenzidine- $\mathrm{H}_{2} \mathrm{O}_{2}$ peroxidase reaction products to neighboring tissues (Courtoy et al. 1983). The staining of the basal plasmalemmae of endothelial cells, alveolar and bronchial cells may be caused by diffusion of diaminoben- 
zidine- $\mathrm{H}_{2} \mathrm{O}_{2}$ reaction products. The dotted reaction products were associated with major cross-bands of collagen fibrils. These observations were similar to those of Torikata et al. (1985) in human lung. Reaction products were also observed of fine filaments, $3-4 \mathrm{~nm}$ in diameter, and fine granules, $10 \mathrm{~nm}$ in width, were located in the interstitium. These findings were identical to those of rat embryonic lung (Rosenkrans et al. 1983). The cisternae of rough endoplasmic reticula of fibroblasts and smooth endoplasmic reticula of endothelial cells were stained. These findings may indicate that both fibroblasts and endothelial cells synthesize fibronectin. The reaction products were not seen in intracytoplasmic organelles in the other cells. However, fibronectin has been recovered from the supernatants of the cultures of fibroblasts, endothelial cells, smooth muscle cells, pulmonary alveolar type II epithelial cells and alveolar macrophages (Muir et al. 1976 ; Jaffe and Mosher 1978; Hedman et al. 1978; Alitalo et al. 1980 ; Villiger et al. 1981 ; Fromme et al. 1982 ; Sage et al. 1983). The reason why the intracytoplasmic organelles of smooth muscle cells, pulmonary alveolar type II epithelial cells and alveolar macrophages were not stained in this study by the antibody against fibronectin was not known. The results of our study agreed with those of the light microscopic immunohistochemistry in various tissues (Stenman and Vaheri 1978; Labat-Robert et al. 1981). Fibronectin had been found to bind to various types of collagens including type I, II, III and IV (Klebe 1974 ; Pearlstein 1976 ; Engvall and Ruoslahti 1977 ; Engvall et al. 1978 ; Dessau et al. 1978) Fibronectin had also been found to be associated with several proteoglycans including heparin (Stathakis and Mosesson 1977; Mosesson 1978), hyaluronic acid (Stenman and Vaheri 1978), heparan sulfate (Laterra et al. 1983) and chondroitin sulfate (Engvall et al. 1978; Perkins et al. 1979). An immunofluorescence study showed that fibronectin was especially abundant in the basal lamina (Linder et al. 1975). Whether or not fibronectin represents a component of basal laminae remains somewhat controversial. Based on the light microscopic studies, several authors (Linder et al. 1975; Stenman and Vaheri 1978; Wartiovaara et al. 1979) concluded that fibronectin was found in basal laminae. However, recent electron microscopic studies have demonstrated that in most tissues, fibronectin is present in the connective tissue adjacent to basal lamina and not in the basal lamina itself (Madri et al. 1980 ; Martinez-Hernandez et al. 1981). This distinction between basal lamina and adjacent matrix is beyond the resolving power of the light microscope (Martinez-Hernandez et al. 1981). Several electron microscopic studies disclosed some fibronectin epitopes within a particular types of the basal lamina-the glomerular basal lamina (Oberley et al. 1979 ; Courtoy et al. 1980 ; Madri et al. 1980 ; Martinez-Hernandez et al. 1981). This findings are interpreted by some (Oberley et al. 1979 ; Courtoy et al. 1980 ) to indicate that fibronectin is part of basal laminae, whereas Amenta et al. (1983) and Martinez-Hernandez et al. (1981) suggest that this is plasma fibronectin trapped in the glomerular filter. Gil and Martinez-Hernandez (1984) support the 
second interpretation in the lung. The frequent localization of fibronectin at the junctions of alveolar and endothelial basal laminae is remarkable and this may indicate some specialized function of fibronectin for this unique point. The authors also noted that epithelial basal lamina, albeit weakly and irregularly, occasionally reacted with antifibronectin antibody. Ultrastructural observations of fibronectin were demonstrated uniformly in basal laminae of normal and fibrotic human lung and normal hamster lung (Torikata et al. 1985), but Rosenkrans et al. (1983) using the peroxidase-antiperoxidase method found essentially no staining of adult rat lung alveolar basal laminae, although 15-day rat embryonic lung alveolar basal laminae were stained focally. Our findings are in agreement with the report by Torikata et al. (1985). Bronchial epithelial and smooth muscle basal laminae, which have minimal filtering function, contain no demonstrable fibronectin in rats (Gil and Martinez-Hernandez 1984). Torikata et al. (1985) found that there was staining of basal laminae of smooth muscle cells. This observation was similar to our findings.

The localization of proteoglycans in pulmonary connective tissue was described in detail elsewhere (Vaccaro and Brody 1979; Takusagawa et al. 1982). According to glycosaminoglycandegrading enzymes and ruthenium red staining, basal lamina contained either heparin or heparan sulfate (Vaccaro and Brody 1979 ; Takusagawa et al. 1982). The basal lamina has been known to contain type IV collagen, heparan sulfate and laminin (Martinez-Hernandez et al. 1982 ; Martinez-Hernandez and Amenta 1983). Fibronectin may bind to either heparan sulfate, type IV collagen or both in basal laminae. Ruthenium red stained fibronectin because it contained sialic acid (Luft 1971; Mosesson 1978; Vaheri and Mosher 1978). Ruthenium red stained with a periodicity lateral granules, 20$30 \mathrm{~nm}$ in diameter on collagen fibrils. This staining pattern of ruthenium red mimicked that of fibronectin. These lateral granules contained chondrotin sulfate (Vaccaro and Brody 1979; Takusagawa et al. 1982). Ruthenium red also rendered visible $3 \mathrm{~nm}$ filaments and $10-80 \mathrm{~nm}$ granules. Either filaments or granules contained hyaluronic acid. In this immunocytochemical procedure, dotted reaction products of the same size of filaments and granules were seen. Therefore these findings suggest that fibronectin binds also to hyaluronic acid. Fibronectin was observed around elastic fibers, not elastic fibers themselves. Fibronectin was codistributed with proteoglycans.

\section{References}

1) Alitalo, K., Hovi, T. \& Vaheri, A. (1980) Fibronectin is produced by human macrophages. J. exp. Med., 151, 602-613.

2) Amenta, P.S., Clark, C.C. \& Martinez-Hernandez, A. (1983) Deposition of fibronectin and laminin in the basement membrane of the rat parietal yolk sac: Immunohistochemical and biosynthetic studies. J. Cell Biol., 96, 104-111.

3) Baum, B.J., McDonald, J.A. \& Crystal, R.G. (1977) Metabolic fate of the major cell surface protein of normal human fibroblasts. Biochem. biophys. Res. Commun., 79, 8- 
15.

4) Clark, J.G., Kuhn, C., III, McDonald, J.A. \& Mecham, R.P. (1983) Lung connective tissue. Int. Rev. Connect. Tissue Res., 10, 249-331.

5) Courtoy, P.J., Kanwar, Y.S., Hynes, R.O. \& Farquhar, M.G. (1980) Fibronectin localization in the rat glomerulus. J. Cell Biol., 87, 691-696.

6) Courtoy, P.J., Picton, D.H. \& Farquhar, M.G. (1983) Resolution and limitations of the immunoperoxidase procedure in the localization of extracellular matrix antigens. J. Histochem. Cytochem., 31, 945-951.

7) Dessau, W., Adelmann, B.C., Timpl, R. \& Martin, G.R. (1978) Identification of the sites in collagen $\alpha$-chains that bind serum anti-gelatin factor (cold-insoluble globulin). Biochem. J., 169, 55-59.

8) Dixon, A.J. \& Burns, J. (1982) Ultrastructural localization of fibronectin in mouse kidney. J. Path., 138, 25-31.

9) Engvall, E. \& Ruoslahti, E. (1977) Binding of soluble form of fibroblast surface protein, fibronectin, to collagen. Int. J. Cancer, 20, 1-5.

10) Engvall, E., Ruoslahti, E. \& Miller, E.J. (1978) Affinity of fibronectin to collagens of different genetic types and to fibrinogen. J. exp. Med., 147, 1584-1595.

11) Fromme, H.G., Voss, B., Pfautsch, M., Grote, M., von Figura, K. \& Beeck, H. (1982) Immunoelectron-microscopic study on the location of fibronectin in human fibroblast cultures. J. Ultrastruct. Res., 80, 264-269.

12) Gil, J. \& Martinez-Hernandez, A. (1984) The connective tissue of the rat lung: Electron immunohistochemical studies. J. Histochem. Cytochem., 32, 230-238.

13) Graham, R.C. \& Karnovsky, M.J. (1966) The early stages of absorption of injected horseradish peroxidase in the proximal tubules of mouse kidney: Ultrastructural cytochemistry by a new technique. J. Histochem. Cytochem., 14, 291-302.

14) Hedman, K., Vaheri, A. \& Wartiovaara, J. (1978) External fibronectin of cultured human fibroblasts is predominantly a matrix protein. J. Cell Biol., 76, 748-760.

15) Hynes, R.O. (1981) Relationships between fibronectin and the cytoskeleton. Cell Surf. Rev., 7, 97-136.

16) Hynes, R.O. \& Yamada, K.M. (1982) Fibronectins : Multifunctional modular glycoproteins. J. Cell Biol., 95, 369-377.

17) Jaffe, E.A. \& Mosher, D.F. (1978) Synthesis of fibronectin by cultured human endothelial cells. J. exp. Med., 147, 1779-1791.

18) Klebe, R.J. (1974) Isolation of a collagen-dependent cell attachment factor. Nature, 250, 248-251.

19) Labat-Robert, J., Birembaut, P., Robert, L. \& Adnet, J.J. (1981) Modification of fibronectin distribution pattern in solid human tumours. Diagn. Histopath., 4, 299306.

20) Laterra, J., Silbert, J.E. \& Culp, L.A. (1983) Cell surface heparan sulfate mediates some adhesive responses to glycosaminoglycan-binding matrices, including fibronectin. J. Cell Biol., 96, 112-123.

21) Linder, E., Vaheri, A., Ruoslahti, E. \& Wartiovaara, J. (1975) Distribution of fibroblast surface antigen in the developing chick embryo. J. $\operatorname{exp.~Med.,~142,~41-49.~}$

22) Luft, J.H. (1971) Ruthenium red and violet. I. Chemistry, purification, methods of use for electron microscopy and mechanism of action. Anat. Rec., 171, 347-368.

23) Madri, J.A., Roll, F.J., Furthmayr, H. \& Foidart, J.M. (1980) Ultrastructural localization of fibronectin and laminin in the basement membranes of the murine kidney. J. Cell Biol., 86, 682-687.

24) Martinez-Hernandez, A. \& Amenta, P.S. (1983) The basement membrane in pathology. Lab. Invest., 48, 656-677.

25) Martinez-Hernandez, A., Marsh, C.A., Clark, C.C., Macarak, E.J. \& Brownell, A.G. (1981) Fibronectin: its relationship to basement membranes. II. Ultrastructural studies in rat kidney. Coll. relat. Res., 1, 405-418. 
26) Martinez-Hernandez, A., Miller, E.J., Damjanov, I. \& Gay, S. (1982) Lamininsecreting yolk sac carcinoma of the rat. Biochemical and electron immunohistochemical studies. Lab. Invest., 47, 247-257.

27)

McLean, I.W. \& Nakane, P.K. (1974) Periodate-lysine para-formaldehydefixatives : a new fixative for immunoelectron microscopy. J. Histochem. Cytochem., 22, 1077-1083.

28) Mosesson, M.W. (1978) Structure of human plasma cold-insoluble globulin and the mechanism of its precipitation in the cold with heparin or fibrin-fibrinogen complexes. Ann. N.Y. Acad. Sci., 312, 11-30.

29) Muir, L.W., Bornstein, P. \& Ross, R. (1976) A presumptive subunit of elastic fiber microfibrils secreted by arterial smooth-muscle cells in culture. Europ. J. Biochem., 64, 105-114.

30) Oberley, T.D., Mosher, D.F. \& Mills, M.D. (1979) Localization of fibronectin within the renal glomerulus and its production by cultured glomerular cells. Amer. J . Path., 96, 651-662.

31) Pearlstein, E. (1976) Plasma membrane glycoprotein which mediates adhesion of fibroblasts to collagen. Nature, 262, 497-500.

32) Perkins, M.E., Ji, T.H. \& Hynes, R.O. (1979) Cross-linking of fibronectin to sulfated proteoglycans at the cell surface. Cell, 16, 941-952.

33) Rosenkrans, W.A., Jr., Albright, J.T., Hausman, R.E. \& Penney, D.P. (1983) Ultrastructural immunocytochemical localization of fibronectin in the developing rat lung. Cell Tissue Res., 234, 165-177.

34) Ruoslahti, E., Engvall, E. \& Hayman, E.G. (1981) Fibronectin : current concepts of its structure and functions. Coll. relat. Res., 1, 95-128.

35) Ruoslahti, E., Pierschbacher, M., Engvall, E., Oldberg, A. \& Hayman, E.G. (1982) Molecular and biological interactions of fibronectin. J. invest. Derm., 79, Suppl. 1, $65 \mathrm{~s}-68 \mathrm{~s}$.

36) Sage, H., Farin, F.M., Striker, G.E. \& Fisher, A.B. (1983) Granular pneumocytes in primary culture secrete several major components of the extracellular matrix. Biochemistry, 22, 2148-2155.

37) Stathakis, N.E. \& Mosesson, M.W. (1977) Interactions among heparin, cold-insoluble globulin, and fibrinogen in formation of the heparin-precipitable fraction of plasma. J. clin. Invest., 60, 855-865.

38) Stenman, S. \& Vaheri, A. (1978) Distribution of a major connective tissue protein, fibronectin, in normal human tissues. $J$. exp. Med., 147, 1054-1064.

39) Takusagawa, K., Ariji, F., Shida, K., Sato, T., Asoo, N. \& Konno, K. (1982) Electron microscopic observations on pulmonary connective tissue stained by ruthenium red. Histochem. $J$., 14, 257-271.

40) Takusagawa, K., Sato, T., Asoo, N. \& Konno, K. (1983) Ultrastructural observations of fibronectin in human lung. $J$. clin. Electron Microscopy., 16, 681-682.

41) Torikata, C., Villiger, B., Kuhn C., III \& McDonald, J.A. (1985) Ultrastructural distribution of fibronectin in normal and fibrotic human lung. Lab. Invest., 52, 399408.

42) Vaccaro, C.A. \& Brody, J.S. (1979) Ultrastructural localization and characterization of proteoglycans in the pulmonary alveolus. Amer. Rev. resp. Dis., 120, 901-910.

43) Vaheri, A. \& Mosher, D.F. (1978) High molecular weight, cell surface-associated glycoprotein (fibronectin) lost in malignant transformation. Biochim. biophys. Acta, 516, 1-25.

44) Villiger, B., Kelley, D.G., Engleman, W., Kuhn, C., III. \& McDonald, J.A. (1981) Human alveolar macrophage fibronectin: Synthesis, secretion, and ultrastructural localization during gelatin-coated latex particle binding. J. Cell Biol., 90, 711-720.

45) Wartiovaara, J., Leivo, I. \& Vaheri, A. (1979) Expression of the cell surfaceassociated glycoprotein, fibronectin, in the early mouse embryo. Dev. Biol., 69, 247- 
Fig. 1. A rough endoplasmic reticulum (arrow) is stained by antisera against fibronectin in a fibroblast. Endothelial basement membrane (arrow-head) is also stained. The bars in this and other figures inidcate $1 \mu \mathrm{m}$ unless stated otherwise.

Fig. 2. Smooth endoplasmic reticulum (arrow), pinocytotic vesicle (arrow-head) and basal plasmalemma are stained by antisera against fibronectin in an endothelial cell. Basement membrane is also stained uniformly.

Fig. 3. Reaction product is seen in a basement membrane beneath a type I epithelial cell in an alveolus. EPI : type I epithelial cell. 

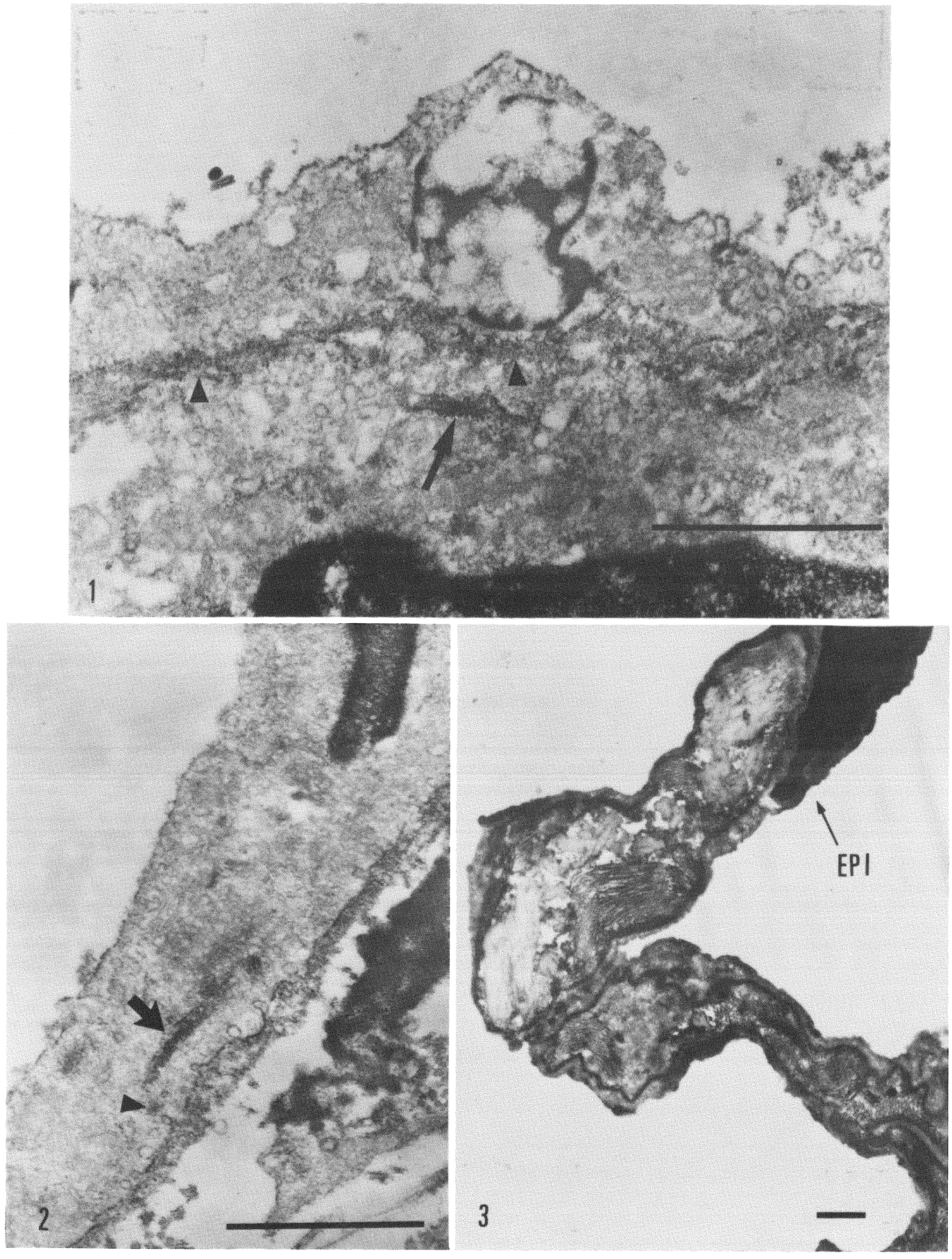
Fig. 4. In a bronchial tree, reaction product is seen in a basement membrane and basal plasmalemma of epithelial cells.

Fig. 5. In an interstitial space, reaction product is observed around a fibroblast and an elastic fiber (arrow) and between bundles of collagen fibrils. 


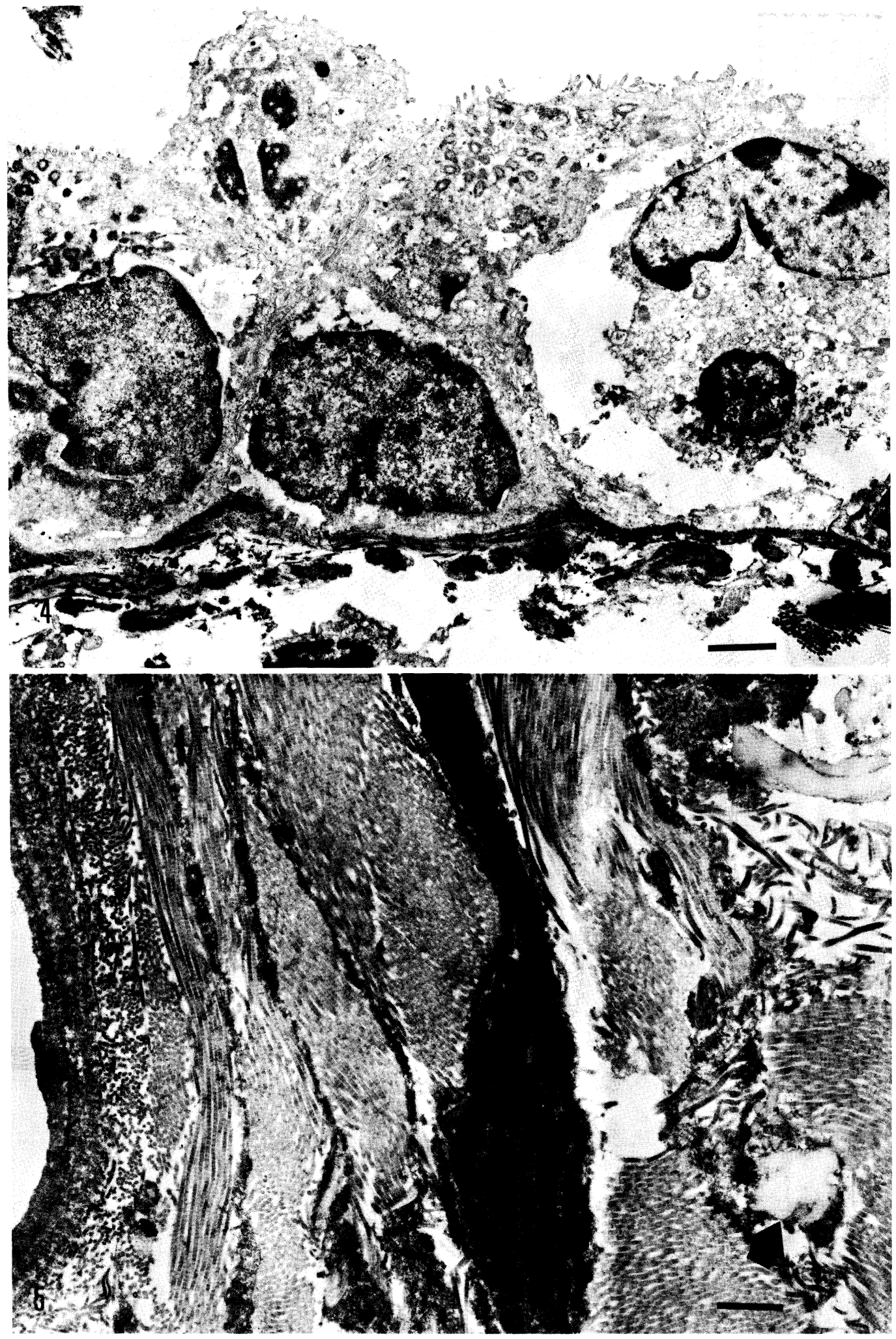


Fig. 6. In an area of loose distribution of collagen fibrils. Reaction product is seen along collagen fibrils, intermediate filaments, $10-20 \mathrm{~nm}$ in diameter (arrow) and fine filaments, 3-4 nm thick (arrow-head).

Fig. 7. A longitudinal section of collagen fibrils. Periodic dotted reaction products (arrow-head) are seen along each of the collagen fibrils and around the elastic fiber (arrow).

Fig. 8. A cross section of collagen fibrils. Reaction product is seen around each of the collagen fibrils. Dotted reaction products (arrow) are seen between each of collagen fibrils. No counterstaining. 

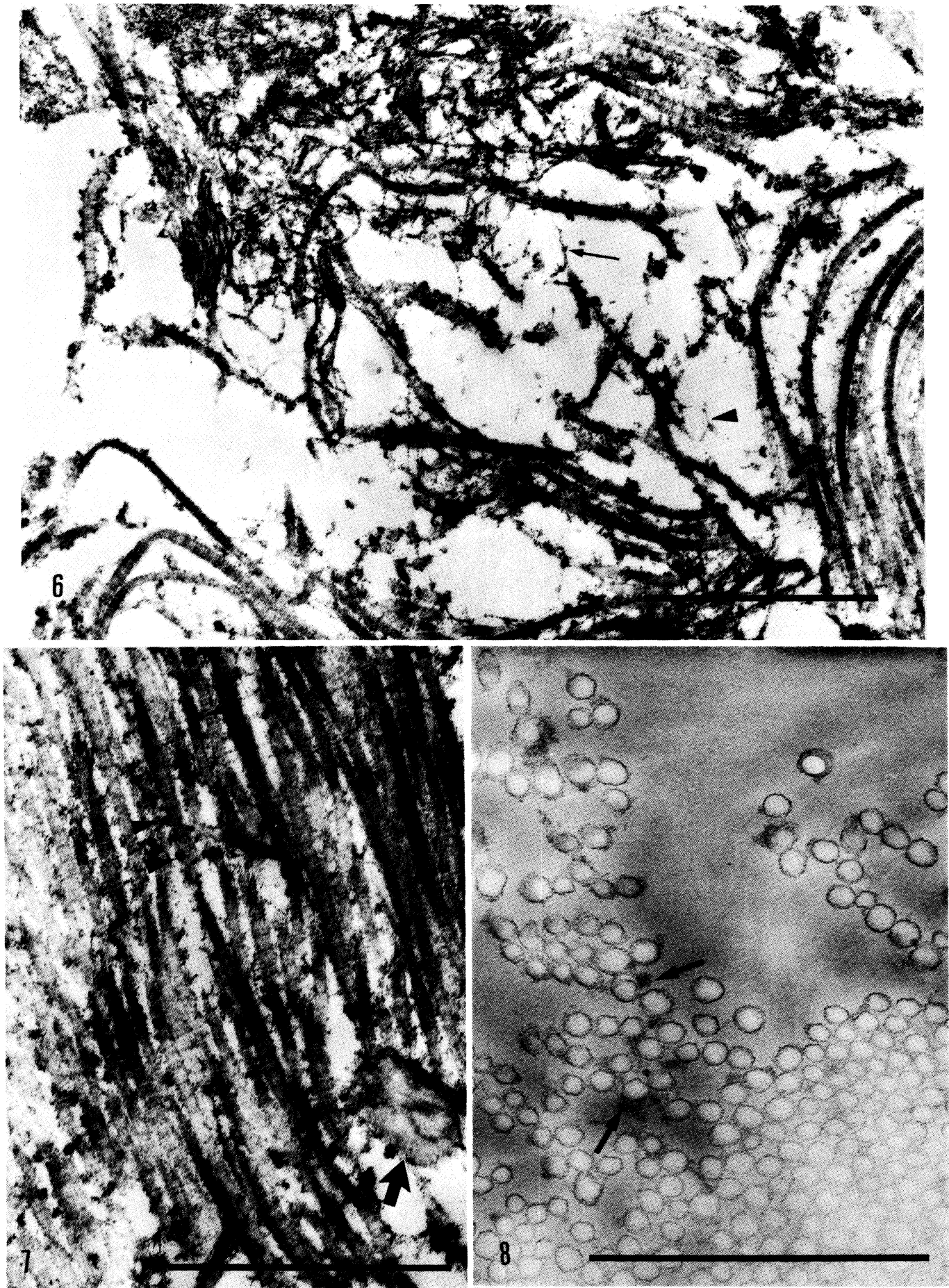
Fig. 9. Wall of a muscular pulmonary artery. Basal lamina and matrix around smooth muscle cells are stained. Empty spaces in the cells are the result of ice crystal formation. Arrows indicate elastic fibers.

Fig. 10. Control of immunoperoxidase staining. No staining is seen. 

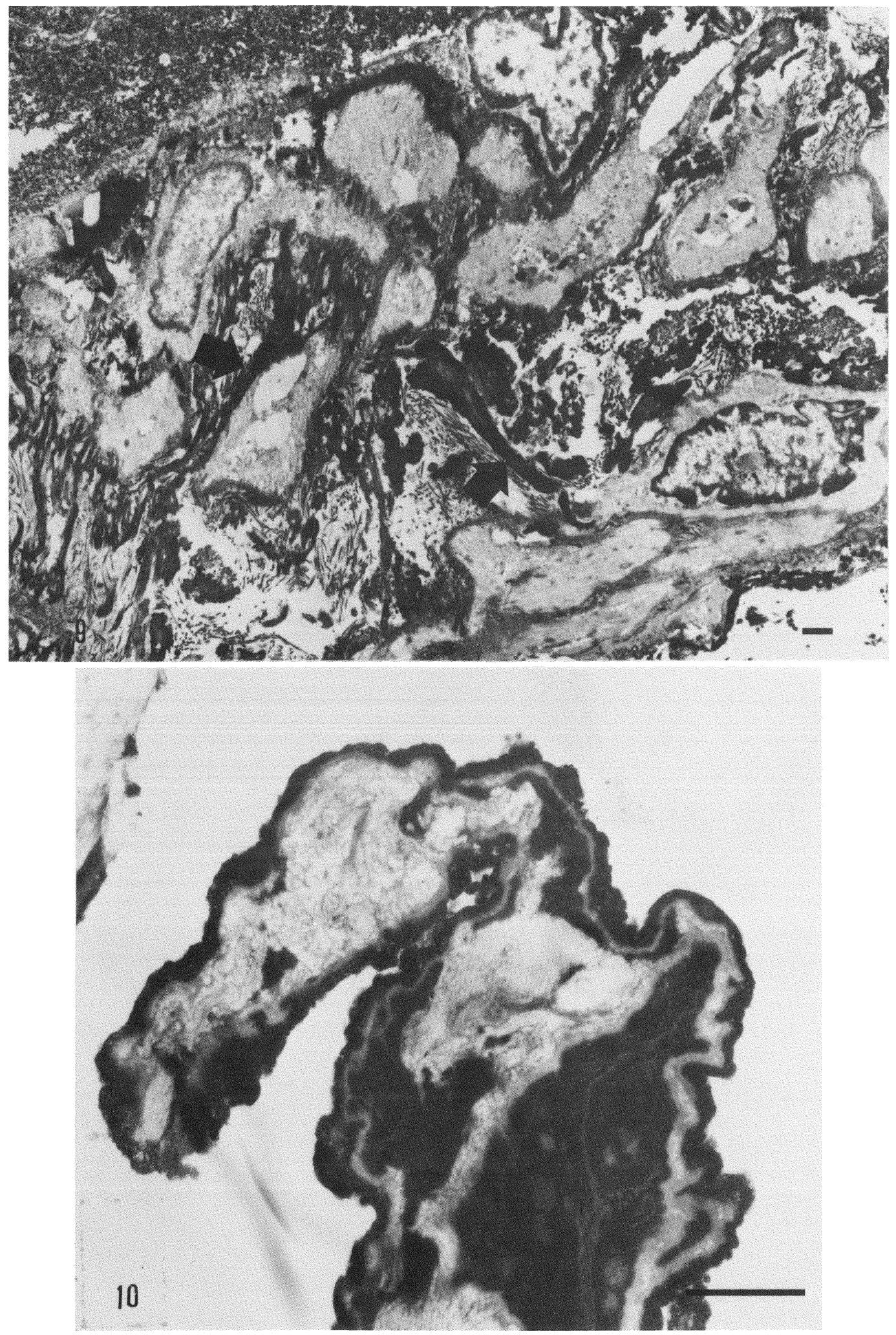